\title{
ANNOTATION
}

\section{The Treatment of Burns}

Recently there has been much discussion and not a little controversy in medical societies and journals about the treatment of burns. While almost all gunshot wounds are to some extent complicated by burning of the injured tissues, there are instances when the burn is caused by some special circumstances, devices or chemicals, such as the airman's burns, burns from the back-flash of large naval guns, from flame-throwers, bomb flashes, phosphorus, cordite, phosgene and mustard gas. Injuries from these sources have stimulated surgeons towards finding suitable methods of protection, such as the asbestos hood and gauntlets used by men in naval gun turrets, and in assessing the best methods of general and local treatment for burns in different parts of the body.

There is agreement about the general treatment of burns by counteracting the shock which comes on some hours after the injury. For this purpose it is necessary to apply warmth from an electric blanket : morphia grs. $\frac{1}{3}$ to $\frac{1}{2}$ repeated when necessary; the administration of plasma, at first a rapid infusion and later by the drip method until the haemoglobin concentration and the blood pressure are normal or nearly so; the administration of oxygen by the Boothby mask and cortin (supra-renal cortical hormonedesoxycorticosterone acetate) intravenously.

About the local treatment of burns there is much difference of opinion and a fair number of therapeutic agents are recommended. The two principal opponents in the controversy are those who favour the use of coagulants such as the tannic acid and silver nitrate preparations, and those who condemn these agents and trust in the application of normal saline packs and saline baths.

There is something to be said in favour of both sides depending on the degree and site of the burn. Careful diagnosis on these two points is essential for correct treatment. For instance, the application of tannic acid preparations to burns of the eyelids renders these important protective structures rigid and contracted, endangering the eye from exposure and rendering any ocular treatment that may be necessary impossible to perform satisfactorily, or even at all. Yet during the past year the eyelids of burnt airmen have been tanned with disastrous results to vision. The use of this agent in third degree burns leads to a dense adherent coagulum, intense oedema of adjacent tissues, and later infection, thus increasing fibrosis and contracture deformity. Some authorities consider that the use of tannic acid on the hands leads to digital necrosis, particularly over the site of joints, and produces rigid spindle-shaped useless fingers. 
The treatment by saline packs and baths requires constant attention, good team work and nursing and absolute asepsis. It is interesting to note that burnt sailors during immersion in the sea experience no appreciable pain. This is also the case when saline baths are administered, particularly by such an ingenious method as the Bunyan-Stannard waterproof silk-cloth envelopes, applicable to the limbs and trunk. For facial burns a gauze mask with apertures for the eyes, nose and mouth is kept continually soaked by a saline drip apparatus, drainage being effected by a jaconette collar. The advocates of this method of treatment maintain that mobility of the tissues is encouraged in the saline bath. When healthy granulations appear and are just below the level of the epidermis, skin grafting is carried out. In clean early cases when the burn is not a deep third degree type, a Thiersch or split skin graft is the best dressing after surgical toilet of the injured area. Pain is immediately relieved and the functional result is generally good.

Tulle gras, a dressing consisting of a $2 \mathrm{~mm}$. mesh impregnated with soft paraffin, balsam of Peru and halibut oil, is valuable for covering the burnt surface and preventing the saline packs from adhering to the tissues.

One authority maintains that saline causes severe maceration and irritation of the tissues and that instead sod. hypochlorite 2.5 per cent. should be used combined with normal saline.

Acriflavine in cod liver oil has been advocated for face burns but condemned by one critic as rapidly producing infection. Some surgeons advise the immobilization of burnt limbs in plaster of Paris for the relief of pain, others think that this encourages stiff joints.

Certain chemicals are suggested for certain types of burns, for instance, copper sulphate 2 per cent. for phosphorus, sodium bicarbonate for cordite, phosgene and mustard gas burns together with bleach for the latter.

In these published discussions the voice of the eye surgeon appears neither to have been raised in recommendation nor in protest. The truth is that at present there is need for thorough and critical clinical investigation comparing the efficacy of various therapeutic agents in different types of burn. In burns affecting the eyelids, particularly in airmen, the lid margins generally escape injury. It would seem that early tarsorrhaphy and Thiersch grafting in such cases may have an important place in treatment, Of the coagulants, tannic acid preparations should be condemned as dangerous. Sodium nitrate 10 per cent. preceded by the application of gentian violet 1 per cent. or triple dye (Aq. gentian violet 2 per cent., brilliant green 1 per cent., acriflavine $0 \cdot 1$ per cent.), justifies a trial in first and second degree burns after preliminary tarsorrhaphy. Saline packs moistened by a continuous drip 
apparatus will require the most constant nursing supervision and strict asepsis. A comparison of the results of early and late skin grafts will be interesting, as also the results of the sulphonamides applied locally and administered by the mouth.

\section{ABSTRACTS}

\section{MISCELLANEOUS}

(1) Metivier, V. M. (Trinidad).-Intra-ocular foreign bodies in Trinidad and Tobago. Carribean Med. Jl., Vol. II, No. 3, 1940.

(1) Metivier reviews his cases of intra-ocular foreign bodies between May, 1932 and May, 1940. In this period 32 patients out of a total of 14,940 new cases had intra-ocular foreign bodies. This incidence is rather higher than the 1 per 1,000 cases in records from Manchester, Wolverhampton and Moorfields.

A Haab giant magnet was procured for the Colony in August, 1934. Before this seven cases had come in in 1932, and one case in 1933. Some of these had to travel to Europe for attention.

Of the author's cases 30 were cases of magnetic foreign bodies. The visual results in 20 cases are given and they were good or very good in 50 per cent. of the patients. The rôle of occupation as the causation factor is shown; and the number of cases among persons employed in local industry is relatively smaller than would be expected. "Apart from the manufacture of sugar and the production and refining of mineral oil and its by-products, major works of importance in the period under review were the construction of the new deep water harbour and the central water supply scheme." The cases from private and hospital practice are shown in tabular form as well as the visual results and a classification of all magnetic foreign bodies, in respect of occupational risk.

R. R. J.

(2) Blumenthal, C. J. (Johannesburg).-Simple detachment of the retina. A review of sixty-eight operated cases. South African Med. Jl., August 24, 1940.

(2) Blumenthal reviews the clinical facts about 68 patients who underwent operation for simple detachment of the retina. $\mathrm{He}$ stresses the importance of very careful pre-operative examination, a thorough study being made of the entire fundus. In spite of an obvious retinal hole or tear it is surprisingly frequent to find a fine split or small hole at another site which if unrecognized would lead to operative failure. 